\title{
Synthesis of densely substituted pyridine derivatives from nitriles by a non-classical [4+2] cycloaddition/1,5-hydrogen shift strategy
}

Wanqing Wu ( $\sim$ cewuwq@scut.edu.cn )

South China University of Technology https://orcid.org/0000-0001-5151-7788

Dandan He

South China University of Technology

Kanghui Duan

South China University of Technology

Yang Zhou

South China University of Technology

Meng Li

South China University of Technology

Huanfeng Jiang

South China University of Technology

Article

Keywords: pyridine derivatives, organic synthesis, medicinal chemistry.

Posted Date: March 3rd, 2021

DOI: https://doi.org/10.21203/rs.3.rs-258126/v1

License: (1) This work is licensed under a Creative Commons Attribution 4.0 International License.

Read Full License 


\section{Abstract}

A novel strategy has been established to assemble an array of densely substituted pyridine derivatives from nitriles and o-substituted aryl alkynes or 1-methyl-1,3-enynes via a non-classical [4 + 2] cycloaddition along with 1,5-hydrogen shift process. The well-balanced affinities of two different alkali metal salts enable the $\mathrm{C}\left(\mathrm{sp}^{3}\right)-\mathrm{H}$ bond activation as well as the excellent chemo- and regioselectivities. This protocol offers a new guide to construct pyridine frameworks from nitriles with $\mathrm{sp}^{3}$-carbon pronucleophiles, and shows potential applications in organic synthesis and medicinal chemistry.

\section{Introduction}

Compounds containing pyridine core structures, not only widely exist in natural products, pharmaceuticals, and functional materials, ${ }^{1-7}$ but also serve as useful and valuable building blocks for metal ligands. ${ }^{8,9}$ For instance, pyridine derivative Actos $\mathbf{I}^{10}$ is a famous drug for the treatment of type 2 diabetes; $\mathrm{Bi}$-(or tri-)pyridines $\mathbf{I I}^{11-15}$ are often used as ligands in metal-catalyzed reactions; Kv1.5 antagonist IIII ${ }^{16}$ and alkaloid papaverine $\mathbf{~} \mathbf{V}^{17}$ are two representative isoquinolines as a promising atrialselective agent and a smooth muscle relaxant, respectively (Fig. 1). Consequently, many synthetic methods have been developed to access this important class of $N$-heterocycles, including metal-free multicomponent syntheses, ${ }^{18}$ transition metal-catalyzed $[2+2+2]$ cycloaddition reactions ${ }^{19-25}$ for pyridines, and transition metal-catalyzed annulations involving alkynes ${ }^{26-30}$ for isoquinolines. Despite these advances, the lack of chemo- and regioselectivities in multicomponent reactions and requirement of complex functionalized substrates as well as harsh reaction conditions ${ }^{22,31-33}$ often limits further exploitation of the synthetic potential of these approachs. The development of novel and efficient strategies toward pyridine derivatives is still highly desirable.

Retrosynthetic analysis of pydirine frameworks suggests that a convenient and straightforward [4 + 2] cycloaddition of $o$-substituted aryl alkynes or its analogues and nitriles would be an attractive alternative to presently reported methods. However, this scenario remains two major challenges: (i) o-Substituted aryl alkynes could undergo intramolecular cyclization to produce indene in the presence of transition metal (Fig. 2A), ${ }^{34-43}$ which enhances the difficulty of intermolecular reaction. (ii) The preferential activation of nitrile in such a system, which means diverting the chemoselectivity of benzylic attack from alkynyl to inert cyano group, is also an intractable issue. As illustrated in Fig. 2B, in the nucleophilic addition of nitriles, the most reported reaction partners have been focused on the highly reactive nitrogen, ${ }^{44-52}$ oxygen, ${ }^{53-61}$ and sulfur nucleophiles till now. ${ }^{62-64}$ For carbon pronucleophiles, the related studies are only limited to $\mathrm{sp}, \mathrm{sp}^{2}$, and $\mathrm{sp}^{3}$ with a-electron withdrawing group (i.e. cyano, carbonyl, ester groups) carbons, though some elegant work has been made by using transition metal catalysts. ${ }^{65-81}$ The difficulty level of these reactions increases drastically when substrates with weakly acidic $\mathrm{C}\left(\mathrm{sp}^{3}\right)-\mathrm{H}$ (especially for $\mathrm{pKa}>40$ in DMSO) bond are utilized, and the methods in this field are rarely developed. ${ }^{82}$ 
To address these challenges, a non-classical [4 + 2] cycloaddition along with 1,5-hydrogen shift strategy is proposed (Fig. 2C). As a strategic fundamental step, our primary task is to identify the balanced conditions for the $\mathrm{C}\left(\mathrm{sp}^{3}\right)$ - $\mathrm{H}$ bond activation, simultaneously avoiding the intrinsic tendency of intramolecular cyclization under the transition metal catalysis. Alkali metals bearing the weaker coordination ability, as a powerful tool for $\mathrm{C}-\mathrm{H}$ bond activation, ${ }^{83-90}$ might have a broadly beneficial impact on our protocol. We envisioned that the $\mathrm{C}\left(\mathrm{sp}^{3}\right)-\mathrm{H}$ bond activation should occur primarily triggered by the amenable alkali metal reagents to form the nucleophilic benzyl or allyl - metal species, which could be trapped rapidly by the suitable electrophile-nitrile. Then a fomal [4+2] cycloaddition would be realized through a consecutive intramolecular alkyne insertion followed by 1,5-hydrogen shift process. Herein we disclose our recent results on this non-classical [4 +2 ] cycloaddition reaction, which provides a direct and atom-economic synthesis of densely substituted pyridines, isoquinolines, and benzothienopyridines with high chemo- and regioselectivity.

\section{Results}

Investigation of reaction conditions. To validate the hypothesis, we commenced our studies by evaluating the reaction between 1-methyl-2-(phenylethynyl)benzene (1a) and benzonitrile (2a) in THF at $100{ }^{\circ} \mathrm{C}$ in the presence of different alkali metal salts (Table 1). Several metal amides in combination with $t$-BuOK were initially tested (entries 1-3), and $\mathrm{LiN}\left(\mathrm{SiMe}_{3}\right)_{2}$ turned out to be the best choice to give product $3 \mathrm{a}$ in $35 \%$ yield. Subsequently, screening of the reaction temperatures identified the optimal $120^{\circ} \mathrm{C}$ (entries 4-6). The examination of other parameters including additive, solvent, and reaction time (entries 7-15) revealed that the reaction proceeded well with $t$-BuOK as additive in CPME for $24 \mathrm{~h}$, improving the yield of 3 a to $65 \%$. Next, investigation of detailed molar ratios of all components indicated that excess nitrile was required due to the consumption of self-cyclotrimerization, and the well-balanced interaction between $\mathrm{LiN}\left(\mathrm{SiMe}_{3}\right)_{2}$ and $t \mathrm{BuOK}$ is the key to the success of reaction (entries 16 and 17, see the Supporting Information for details). Finally, the reaction of 1a: $2 \mathrm{a}: \mathrm{LiN}\left(\mathrm{SiMe}_{3}\right)_{2}: t$-BuOK in a molar ratio of 1: 3: 2: 1.5 gave $3 \mathbf{a}$ in $80 \%$ isolated yield (entry 17 ).

Substrate scope. Having established the optimal reaction conditions, the scope of this [4+2] cycloaddition reaction was then explored (Table 2). Pleasingly, o-substituted aryl alkynes 1 with electron-donating substituents, such as $-\mathrm{Me}$, $-t-\mathrm{Bu}$, and $-\mathrm{OMe}$ at the 4-position of aromatic ring $\mathrm{Ar}^{1}$, were well compatible in this reaction, and the desired products (3b-3d) were isolated in 60-78\% yields. o-Substituted aryl alkyne bearing 3-Me substituted $\mathrm{Ar}^{1}$ also reacted with $2 \mathbf{a}$ to afford $3 \mathbf{e}$ in a slightly descending yield, while the substrates containing halogens were relatively limited (e.g., 3f). The reaction proceeded as well with a larger aromatic $\mathrm{Ar}^{1}$, 2-naphthyl, providing the corresponding adduct $\mathbf{3 g}$ in $65 \%$ yield. Moreover, when using a series of functionalized nitriles 2 as reactants, including $p$-Me, $p-t-\mathrm{Bu}, p-\mathrm{OMe}, p-\mathrm{Ph}$, and $m-t-\mathrm{Bu}$ substituted benzonitriles, isoquinoline derivatives (3h-3l) with moderate to good yields (48-82\%) were obtained The structure of $\mathbf{3 i}$ was confirmed unambiguously by $\mathrm{X}$-ray diffraction. The substituent $\mathrm{R}^{1}$ on arylmethane ring could be varied as well $(3 m-3 p)$ under the standard conditions. When $R^{2}$ was replaced 
by a cyano group, contributing to relatively acidic benzyl protons, the cycloadditions occurred smoothly in the absence of lithium amide (3q-3r). In addition, the introduction of a sterically demanding phenyl at the benzylic position enabled the release of larger conjugated isoquinoline derivative in $45 \%$ yield (3s). Benzylic $\mathrm{C}-\mathrm{H}$ bond with a methyl group at the benzylic position could also be functionalized in this reaction albeit in $28 \%$ yield (3t). However, the substrate with a phenoxy group $\mathrm{R}^{2}$ failed to undergo the desired [4 +2] cycloaddition reaction (3u).

To further expand the generality of this method, a series of functionalized heteroaromatic substrates were utilized to test the reactivity (Table 3). The result indicated 3-alkynyl-2-methylbenzo[b]thiophene (4) with different substituents $(\mathrm{H}, \mathrm{OMe}, \mathrm{N}, \mathrm{N}-2 \mathrm{Me})$ on the aromatic ring $\mathrm{Ar}^{1}$ were well tolerated, converting to the fused heterocycle benzothienopyridine derivatives $\mathbf{5 a - 5 c}$ in $71-90 \%$ yields. Gratifyingly, halogens, such as $4-\mathrm{F}, 4-\mathrm{Cl}, 4-\mathrm{Br}, 3-\mathrm{Cl}$ and 3,5-2F, could also be installed on the same aromatic ring $\mathrm{Ar}^{1}$, and the corresponding products $\mathbf{5 d - 5} \mathbf{h}$ were obtained in acceptable to good yields. The generated heteroaryl halides provided versatile synthetic handles for further derivatization. Moreover, the synthesis of compounds $\mathbf{5 j - 5} \mathbf{n}$ with $53-71 \%$ yields suggested that the compatibility of substituents on nitrile has been extended to - $\mathrm{Cl},-\mathrm{CF}_{3},-\mathrm{OMOM}$, and -1,3-dioxolane derived fromaldehyde group, thus providing a platform for additional functionalization. 3,5-Disubstituted benzonitrile and 2-naphthonitrile were also applicable in this system, and the desired products $\mathbf{5 0}$ and $\mathbf{5 p}$ were delivered in $72 \%$ and $66 \%$ yields, respectively. It should be noted that the pincer-type or dipyridyl-type nitrogen ligands $\mathbf{5 i}, \mathbf{5 q}$ and $\mathbf{5 r}$ could be constructed in good yields. More importantly, this protocol was also applied to the late-stage functionalization of drug molecule citalopram, which is a selective serotonin-uptake inhibitor, and the compound $\mathbf{5} \boldsymbol{s}$ was provided in $67 \%$ yield, exhibiting the potential in pharmaceutical research.

Specifically, this method also applied to the substrates bearing less acidic $\mathrm{C}\left(\mathrm{sp}^{3}\right)$-H bonds. For instance, the desired reaction of (Z)-pent-3-en-1-yn-1-ylbenzene (6) and $\mathbf{2} \mathbf{a}$ was carried out successfully after simply adjusting the reaction conditions to afford the product 2-benzyl-6-phenylpyridine (7a) in $60 \%$ yield (Table 4). Then substituted nitriles with 4- $t \mathrm{Bu}, 4-\mathrm{OMe},-\mathrm{Ph}, 3-\mathrm{Me}$ and $3,5-2 \mathrm{Me}$ were further examined, and a series of 2,6-disubstituted pyridines were isolated in $35-58 \%$ yields (7b-7f). To our knowledge, this is the rare example of demonstrating possibility of formal allylic $\mathrm{C}-\mathrm{H}$ bond addition to nitrile.

To further illustrate the value of this method, gram-scale experiments and postderivatizations of the newly formed products were conducted (Fig. 3). When the reaction proceeded at a $5 \mathrm{mmol}$ scale, the desired products $\mathbf{3} \mathbf{c}$ and $\mathbf{5 a}$ were obtained in almost unaffected yields even with reduced amount of nitrile. Additionally, inspired by the importance of organic fluorophores in a number of fields including materials science and biology, two new solid-state-emitting organic molecules $\mathbf{8}$ and $\mathbf{9}$ were synthesized. Tetraarylethylene $\mathbf{8}$ was obtained by a single Suzuki-Miyaura coupling of $\mathbf{5 f}$ with $\mathbf{6 0 \%}$ yield, while the successive hydrolysis and condensation reaction of $\mathbf{5 n}$ gave compound $\mathbf{9}$ in $\mathbf{9 5 \%}$ total yield. Studies on the photophysical propertie showed the absorption maxima of 8 and 9 were about $336 \mathrm{~nm}$ and $385 \mathrm{~nm}$ in DMSO solution, respectively, and the corresponding intense emission peaks were at $404 \mathrm{~nm}$ and $587 \mathrm{~nm}$ in powder, which might find applications in construction of functional materials. 
Mechanistic investigations. To shed light on the reaction mechanism, several control experiments were performed. Firstly, when ${ }^{15} \mathrm{~N}$-labeled benzonitrile was emplyed under the standard reaction conditions, $3 c\left({ }^{15} \mathrm{~N}\right)$ and $3 \mathbf{c}\left({ }^{14} \mathrm{~N}\right)$ were detected respectively with the ratio of $49: 51$ by HRMS analysis, elucidating that the nitrogen atom in the pyridine framework came not only from nitrile but also $\mathrm{LiN}\left(\mathrm{SiMe}_{3}\right)_{2}$ (Fig. 4a). Then, the studies of introducing exogenous halogens $\mathrm{PhX}(\mathrm{X}=\mathrm{F}, \mathrm{Cl}, \mathrm{or} \mathrm{Br})$ to the reaction system showed that fluorobenzene slightly reduced the yield of $\mathbf{3 c}$, while chlorobenzene and bromobenzene greatly suppressed the transformation, indicating that the coordination of $\mathrm{PhX}$ to the alkali metals might account for the inhibitory effect (Fig. 4b). ${ }^{83}$ Next, a Hammett study was carried out using various substituted benzonitriles to investigate a rate dependence on the electronic effect of nitrile (Fig. 4c). A linear

relationship with negative $\rho$ value of -2.95 was observed when relative rates with $-\mathrm{OMe},-\mathrm{Me},-\mathrm{H},-\mathrm{Cl}$, and $\mathrm{CF}_{3}$ substituted benzonitriles $\left[\log \left(k_{\mathrm{X}} / k_{\mathrm{H}}\right)\right]$ were plotted against the substituent constant $(\sigma)$. These results suggested that the electron-donating group should facilitate the intermolecular addition step, which was consistent with the reactivity of the nitrile substrates reported in Tables 2-4. Finally, the kinetic order experiments (Fig. 4d) showed a first-order dependence on concentrations of $\mathbf{2 a}$, which indicated that the formation of metalated imine by quickly capturing benzylic-metal species with nitrile should be the ratelimiting step. However, the benzyl substrate 1c, theoretically accelerating an equilibrium formation of benzylic-metal species, exhibited the negative-order kinetic effect in the reaction. Moreover, the rates of both $t$-BuOK and $\mathrm{LiN}\left(\mathrm{SiMe}_{3}\right)_{2}$ could not be described by a single power function. These observations aligned with the optimization data possibly portend the well-balanced interactions between base and additive for benzylic or allylic $\mathrm{C}\left(\mathrm{sp}^{3}\right)$-H activation. This cooperative interaction was further proved with hydrogen/deuterium exchange experiment of 1c-d (Fig. S1).

Based on the above investigation and literature reports, ${ }^{82-90}$ a possible mechanism is proposed in Fig. 5. Initially, the $\mathrm{C}\left(\mathrm{sp}^{3}\right)-\mathrm{H}$ bond of $\mathbf{1 a}$ is activated by the interaction of $\mathrm{LiN}\left(\mathrm{SiMe}_{3}\right)_{2}$ and $t$-BuOK to afford a nucleophilic benzylic-metal species $\mathbf{A}$, which is quickly trapped by nitrile $\mathbf{2} \mathbf{a}$ to form the metalated imine intermediate $\mathbf{B}$. Next, subsequent addition of intermediate $\mathbf{B}$ to the alkyne achieves the cyclization. The resulting alkenyl-metal species $\mathbf{C}$ undergoes protonation and 1,5-hydrogen shift process to deliver the desired $\mathbf{3} \mathbf{a}$. Alternatively, the reaction could proceed by either protonation or silylation of intermediate $\mathbf{B}$ with $\mathrm{HN}\left(\mathrm{SiMe}_{3}\right)_{2}$ from the initial deprotonation equilibrium, generating imine $\mathrm{D}^{8}{ }^{82}$ In the presence of $\mathrm{Li} / \mathrm{KN}\left(\mathrm{SiMe}_{3}\right)_{2}$, the imine $\mathbf{D}$ would undergo a reversible addition, silyl migration, and elimination pathway to release nitrogen-exchanged intermediate $F^{91,92}$ followed by the further silyl transfer and cyclization to give nitrogen-exchanged intermediate $\mathbf{G}$.

\section{Discussion}

In summary, we have developed a non-classical [4 +2] cycloaddition reaction of benzylic and allylic prenucleophiles with nitriles, leading to a range of $N$-heterocycles bearing pyridine frameworks and various functional groups. This protocol hinges on the cooperative interaction of alkali metals to trigger benzylic and allylic $\mathrm{C}-\mathrm{H}$ bond activation, simultaneously avoiding the inherent intramolecular cyclization. 
The Hammett experiment and kinetic analysis show that the addition of benzylic- or allylic-metal species to nitrile is the rate-limiting step. Notably, this protocol provides a new guide for the synthesis of functionalized pyridines from $\mathrm{sp}^{3}$-carbon pronucleophiles with nitriles, which implies the potential value in organic synthesis and medicinal chemistry.

\section{Method}

Procedure for the synthesis of product 3. In a glovebox, an oven-dried Schlenk tube equipped with a magnetic stirring bar was added a mixture of $o$-substituted aryl alkyne $1(0.2 \mathrm{mmol})$, nitrile $2(0.6 \mathrm{mmol})$, base $(0.4 \mathrm{mmol})$, additive $(0.3 \mathrm{mmol})$ dissolved in $1.0 \mathrm{~mL}$ of dry CPME. The Schlenk tube was sealed with a plug and removed from the glovebox. The mixture was allowed to stir at $120^{\circ} \mathrm{C}$ under $\mathrm{N}_{2}$ for $24 \mathrm{~h}$. The reaction mixture was cooled to room temperature and quenched by $10 \mathrm{~mL}$ water. The product was extracted with ethyl acetate $(10 \mathrm{~mL} \times 3)$. The organic phase was dried over $\mathrm{Na}_{2} \mathrm{SO}_{4}$ and concentrated in vacuum. The resulting residue was purified by silica gel column chromatography using petroleum ether/ethyl acetate (100:1-10:1 v/v) as eluent to afford the corresponding product 3 .

Procedure for the synthesis of product 5. In a glovebox, an oven-dried Schlenk tube equipped with a magnetic stirring bar was added a mixture of $o$-substituted aryl alkyne $4(0.2 \mathrm{mmol})$, nitrile $2(0.6 \mathrm{mmol})$, base $(0.4 \mathrm{mmol})$, additive $(0.24 \mathrm{mmol})$ dissolved in $0.5 \mathrm{~mL}$ of dry CPME. The Schlenk tube was sealed with a plug and removed from the glovebox. The mixture was allowed to stir at $120^{\circ} \mathrm{C}$ under $\mathrm{N}_{2}$ for $24 \mathrm{~h}$. The reaction mixture was cooled to room temperature and quenched by $10 \mathrm{~mL}$ water. The product was extracted with ethyl acetate $(10 \mathrm{~mL} \times 3)$. The organic phase was dried over $\mathrm{Na}_{2} \mathrm{SO}_{4}$ and concentrated in vacuum. The resulting residue was purified by silica gel column chromatography using petroleum ether/ethyl acetate (100:1-10:1 v/v) as eluent to afford the corresponding product 5.

Procedure for the synthesis of product 7. In a glovebox, an oven-dried Schlenk tube equipped with a magnetic stirring bar was added a mixture of 1-methyl-1,3-enyne $6(0.2 \mathrm{mmol})$, nitrile $2(0.6 \mathrm{mmol})$, base $(0.4 \mathrm{mmol})$, additive $(0.24 \mathrm{mmol})$ dissolved in $0.5 \mathrm{~mL}$ of dry 1,4-dioxane. The Schlenk tube was sealed with a plug and removed from the glovebox. The mixture was allowed to stir at $120^{\circ} \mathrm{C}$ under $\mathrm{N}_{2}$ for $12 \mathrm{~h}$. The reaction mixture was cooled to room temperature and quenched by $10 \mathrm{~mL}$ water. The product was extracted with ethyl acetate $(10 \mathrm{~mL} \times 3)$. The organic phase was dried over $\mathrm{Na}_{2} \mathrm{SO}_{4}$ and concentrated in vacuum. The resulting residue was purified by silica gel column chromatography using petroleum ether/ethyl acetate (100:1-50:1 v/v) as eluent to afford the corresponding product 7.

\section{Declarations}

\section{Data availability}

The authors declare that the data supporting the findings of this study are available within the article and Supplementary Information, as well as from the authors upon reasonable request. The X-ray crystallographic coordinate for structure $3 i$ reported in this study has been deposited at the Cambridge 
Crystallographic Data Centre (CCDC), under CCDC 2051390. The data can be obtained free of charge from The Cambridge Crystallographic Data Centre via www.ccdc.cam.ac.uk/data冈request/cif.

\section{Competing interests}

The authors declare no competing interests.

\section{Author contributions}

D.H. and W.W. designed the project. D.H., H.J., and W.W. co-wrote the manuscript, analyzed the data, discussed the results, and commented on the manuscript. D. H., K.D., and Y.Z. performed the experiments. All authors contributed to discussions.

\section{Acknowledgements}

The authors thank the National Key Research and Develop-ment Program of China (2016YFA0602900), the National Nat-ural Science Foundation of China (22071063), and the Fundamental Research Funds for the Central Universities (2019PY05 and x2hgD2200520) for financial support.

\section{References}

1. Vacher, B., Bonnaud, B., Funes, P., Jubault, N., Koek, W., Assié, M.-B., Cosi, C. \& Kleven, M. Novel derivatives of 2-pyridinemethylamine as selective, potent, and orally active agonists at $5-\mathrm{HT}_{1 \mathrm{~A}}$ receptors. J. Med. Chem. 42, 1648-1660 (1999).

2. O’Hagan, D. Pyrrole, pyrrolidine, pyridine, piperidine and tropane alkaloids. Nat. Prod. Rep. 17, 435446 (2000).

3. Buckley, G. M., Cooper, N., Davenport, R. J., Dyke, H. J., Galleway, F. P., Gowers, L., Haughan, A. F., Kendall, H. J., Lowe, C., Montana, J. G., Oxford, J., Peake, J. C., Picken, C. L., Richard, M. D., Sabin, V., Sharpe, A. \& Warneck, J. B. H. 7-Methoxyfuro[2,3-c]pyridine-4-carboxamides as PDE4 inhibitors: a potential treatment for asthma. Bioorg. Med. Chem. Lett. 12, 509-512 (2002).

4. Horiuch, M., Murakami, C., Fukamiya, N., Yu, D., Chen, T.-H., Bastow, K. F., Zhang, D.-C., Takaishi, Y., Imakura, Y. \& Lee, K.-H. Tripfordines A-C, Sesquiterpene pyridine alkaloids from tripterygium wilfordii, and structure anti-HIV activity relationships of tripterygium alkaloids. J. Nat. Prod. 69, 1271-1274 (2006).

5. Lu, C.-M., Chen, Y.-L., Chen, H.-L., Chen, C.-A., Lu, P.-J., Yang, C.-N. \& Tzeng, C.-C. Synthesis and antiproliferative evaluation of certain indolo[3,2-c]quinoline derivatives. Bioorg. Med. Chem. 18, 1948-1957 (2010).

6. Duffy, C. D., Maderna, P., McCarthy, C., Loscher, C. E., Godson, C. \& Guiry, P. J. Synthesis and biological evaluation of pyridine-containing lipoxin $\mathrm{A}_{4}$ analogues. ChemMedChem. 5, 517-522 (2010).

7. de Ruiter, G., Lahav, M. \& van der Boom, M. E. Pyridine coordination chemistry for molecular assemblies on surfaces. Acc. Chem. Res. 47, 3407-3416 (2014). 
8. Chelucci, G. Synthesis and application in asymmetric catalysis of camphor-based pyridine ligands. Chem. Soc. Rev. 35, 1230-1243 (2006).

9. Yamada, S., Kaneda, T., Steib, P., Murakami, K. \& Itami. K. Dehydrogenative synthesis of 2,2'-bipyridyls through regioselective pyridine dimerization. Angew. Chem. Int. Ed. 58, 8341-8345 (2019).

10. Binda, C., Aldeco, M., Geldenhuys, W. J., Tortorici, M., Mattevi, A. \& Edmondson, D. E. Molecular insights into human monoamine oxidase B inhibition by the glitazone antidiabetes drugs. ACS Med. Chem. Lett. 3, 39-42 (2012).

11. Kaes, C., Katz, A. \& Hosseini, M. W. Bipyridine: the most widely used ligand. a review of molecules comprising at least two 2,2'-bipyridine units. Chem. Rev. 100, 3553-3590 (2000).

12. Prier, C. K., Rankic, D. A. \& MacMillan, D. W. C. Visible light photoredox catalysis with transition metal complexes: applications in organic synthesis. Chem. Rev. 113, 5322-5363 (2013).

13. Kawakami, T. Murakami, K. \& Itami, K. Catalytic C-H imidation of aromatic cores of functional molecules: ligand-accelerated $\mathrm{Cu}$ catalysis and application to materials- and biology-oriented aromatics. J. Am. Chem. Soc. 137, 2460-2463 (2015).

14. Paul, B., Shee, S., Panja, D., Chakrabarti, K. \& Kundu, S. Direct synthesis of $N, N$-dimethylated and $\beta$-methyl $N, N$-dimethylated amines from nitriles using methanol: experimental and computational studies. ACS Catal. 8, 2890-2896 (2018).

15. Yue, H., Zhu, C., Shen, L., Geng, Q., Hock, K. J., Yuan, T., Cavallo, L. \& Rueping, M. Nickel-catalyzed C$\mathrm{N}$ bond activation: activated primary amines as alkylating reagents in reductive cross-coupling. Chem. Sci. 10, 4430-4425 (2019).

16. Trotter, B. W., Nanda, K. K., Kett, N. R., Regan, C. P., Lynch, J. J., Stump, G. L., Kiss, L., Wang, J., Spencer, R. H., Kane, S. A., White, R. B., Zhang, R., Anderson, K. D., Liverton, N. J., Mclntyre, C. J., Beshore, D. C., Hartman, G. D. \& Dinsmore, C. J. Design and synthesis of novel isoquinoline-3-nitriles as orally bioavailable Kv1.5 antagonists for the treatment of atrial fibrillation. J. Med. Chem. 49, 6954-6957 (2006).

17. Izzo, A. A., Mascolo, N., Costa, M. \& Capasso, F. Effect of papaverine on synaptic transmission in the guinea-pig ileum. Br. J. Pharmacol. 121, 768-772 (1997).

18. Allais, C., Grassot, J.-M., Rodriguez, J. \& Constantieux, T. Metal-free multicomponent syntheses of pyridines. Chem. Rev. 114, 10829-10868 (2014).

19. Varela, J. A. \& Saá, C. Construction of pyridine rings by metal-mediated [2 + 2+2] cycloaddition. Chem. Rev. 103, 3787-3801 (2003).

20. Heller, B. \& Hapke, M. The fascinating construction of pyridine ring systems by transition metalcatalysed [2 + 2 + 2] cycloaddition reactions. Chem. Soc. Rev. 36, 1085-1094 (2007).

21. Tan, J.-F., Bormann, C. T., Perrin, F. G., Chadwick, F. M., Severin, K. \& Cramer, N. Divergent synthesis of densely substituted arenes and pyridines via cyclotrimerization reactions of alkynyl triazenes. J. Am. Chem. Soc. 141, 10372-10383 (2019).

22. Thompson, S. K. \& Hoye, T. R. The aza-hexadehydro-Diels-Alder reaction. J. Am. Chem. Soc. 141, 19575-19580 (2019). 
23. Sheng, J., Wang, Y., Su, X., He, R. \& Chen, C. Copper-catalyzed [2+2+2] modular synthesis of multisubstituted pyridines: alkenylation of nitriles with vinyliodonium salts. Angew. Chem. Int. Ed. 56, 4824-4828 (2017).

24. Kashima, K., Teraoka, K., Uekusa, H., Shibata, Y. \& Tanaka, K. Rhodium-catalyzed atroposelective [2 + $2+2$ ] cycloaddition of ortho-substituted phenyl diynes with nitriles: effect of ortho substituents on regio- and enantioselectivity. Org. Lett. 18, 2170-2173 (2016).

25. Ohashi, M., Takeda, I., Ikawa, M. \& Ogoshi, S. Nickel-catalyzed dehydrogenative [4 + 2] cycloaddition of 1,3-dienes with nitriles. J. Am. Chem. Soc. 133, 18018-18021 (2011).

26. Fischer, D., Tomeba, H., Pahadi, N. K., Patil, N. T., Huo, Z. \& Yamamoto, Y. lodine-mediated electrophilic cyclization of 2-alkynyl-1-methylene azide aromatics leading to highly substituted isoquinolines and its application to the synthesis of norchelerythrine. J. Am. Chem. Soc. 130, 15720-15725 (2008).

27. Fukutani, T., Umeda, N., Hirano, K., Satoh, T. \& Miura, M. Rhodium-catalyzed oxidative coupling of aromatic imines with internal alkynes via regioselective $\mathrm{C}-\mathrm{H}$ bond cleavage. Chem. Commun. 51415143 (2009).

28. Shi, Z., Koester, D. C., Boultadakis-Arapinis, M. \& Glorius, F. Rh(III)-Catalyzed synthesis of multisubstituted isoquinoline and pyridine $\mathrm{N}$-Oxides from oximes and diazo compounds. J. Am. Chem. Soc. 135, 12204-12207 (2013).

29. He, R., Huang, Z.-T., Zheng, Q.-Y. \& Wang, C. Manganese-catalyzed dehydrogenative [4 + 2] annulation of $\mathrm{N}-\mathrm{H}$ imines and alkynes by $\mathrm{C}-\mathrm{H} / \mathrm{N}-\mathrm{H}$ activation. Angew. Chem. Int. Ed. 53, 4950-4953 (2014).

30. Sun, B., Yoshino, T., Kanai, M. \& Matsunaga, S. Cp*Colll Catalyzed site-selective $\mathrm{C}-\mathrm{H}$ activation of unsymmetrical $o$-acyl oximes: synthesis of multisubstituted isoquinolines from terminal and internal alkynes. Angew. Chem. Int. Ed. 54, 12968-12972 (2015).

31. Zheng, L., Ju, J., Bin, Y. \& Hua, R. Synthesis of isoquinolines and heterocycle-fused pyridines via three-component cascade reaction of aryl ketones, hydroxylamine, and alkynes. J. Org. Chem. 77, 5794-5800 (2012).

32. Chen, M. Z. \& Micalizio, G. C. Three-component coupling sequence for the regiospecific synthesis of substituted pyridines. J. Am. Chem. Soc. 134, 1352-1356 (2012).

33. He, Z., Dobrovolsky, D., Trinchera, P. \& Yudin, A. K. Synthesis of multisubstituted pyridines. Org. Lett. 15, 334-337 (2013).

34. Nakamura, I., Bajracharya, G. B., Wu, H., Oishi, K., Mizushima, Y., Gridnev, I. D. \& Yamamoto, Y. Catalytic cyclization of $o$-alkynylbenzaldehyde acetals and thioacetals. unprecedented activation of the platinum catalyst by olefins. scope and mechanism of the reaction. J. Am. Chem. Soc. 126, 15423-15430 (2004).

35. Nakamura, I., Mizushima, Y., Gridnev, I. D. \& Yamamoto, Y. Stepwise delivery of two methoxy groups of arylaldehyde acetals across the phenyl ring. vacant site-controlled palladium catalysis. J. Am. Chem. Soc. 127, 9844-9847 (2005).

36. Dubé, P. \& Toste, F. D. Synthesis of indenyl ethers by gold(I)-catalyzed intramolecular carboalkoxylation of alkynes. J. Am. Chem. Soc. 128, 12062-12063 (2006). 
37. Bajracharya, G. B., Pahadi, N. K., Gridnev, I. D. \& Yamamoto, Y. $\mathrm{PtBr}_{2}$-Catalyzed transformation of allyl(o-ethynylaryl)carbinol derivatives into functionalized indenes. formal $\mathrm{sp}^{3} \mathrm{C}-\mathrm{H}$ bond activation. J. Org. Chem. 71, 6204-6210 (2006).

38. Zhang, D., Liu, Z., Yum, E. K. \& Larock, R. C. Synthesis of indenes by the transition metal-mediated carboannulation of alkynes. J. Org. Chem. 72, 251-262 (2007).

39. Odedra, A., Datta, S. \& Liu, R.-S. Ruthenium-catalyzed cyclization of 2-alkyl-1-ethynylbenzenes via a 1,5-hydrogen shift of ruthenium-vinylidene intermediates. J. Org. Chem. 72, 3289-3292 (2007).

40. Tobisu, M., Nakai, H. \& Chatani, N. Platinum and ruthenium chloride-catalyzed cycloisomerization of 1-alkyl-2-ethynylbenzenes: interception of $\pi$-activated alkynes with a benzylic $\mathrm{C}-\mathrm{H}$ bond. J. Org. Chem. 74, 5471-5475 (2009).

41. Yang, S., Li, Z., Jian, X. \& He, C. Platinum(II)-catalyzed intramolecular cyclization of $o$-substituted aryl alkynes through sp ${ }^{3} \mathrm{C}-\mathrm{H}$ activation. Angew. Chem. Int. Ed. 48, 3999-4001 (2009).

42. Morán-Poladura, P., Rubio, E. \& González, J. M. Intramolecular C-H activation through gold(I)catalyzed reaction of iodoalkynes. Angew. Chem. Int. Ed. 54, 3052-3055 (2015).

43. Nahide, P. D., Jiménez-Halla, J. O. C., Wrobel, K., Solorio-Alvarado, C. R., Alvarado, R. O. \& YahuacaJuárez, B. Gold(I)-catalysed high-yielding synthesis of indenes by direct $\mathrm{C}_{\mathrm{sp} 3}-\mathrm{H}$ bond activation. Org. Biomol. Chem. 16, 7330-7335 (2018).

44. Su, X., Chen, C., Wang, Y., Chen, J., Louac, Z. \& Li, M. One-pot synthesis of quinazoline derivatives via $[2+2+2]$ cascade annulation of diaryliodonium salts and two nitriles. Chem. Commun. 49, 67526754 (2013).

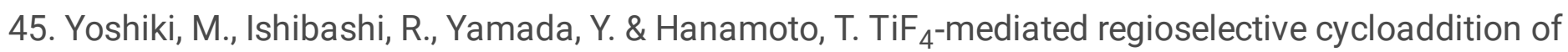
2-(trifluoromethyl)- $N$-tosylaziridine to nitriles. Org. Lett. 16, 5509-5511 (2014).

46. Huang, S., Shao, Y., Zhang, L. \& Zhou, X. Cycloamidination of aminoalkenes with nitriles: synthesis of substituted 2-imidazolines and tetrahydropyrimidines. Angew. Chem. Int. Ed. 54, 14452-14456 (2015).

47. Das, U. K., Shimon, L. J. W. \& Milstein, D. Imidazole synthesis by transition metal free, base-mediated deaminative coupling of benzylamines and nitriles. Chem. Commun. 53, 13133-13136 (2017).

48. Wang, X., He, D., Huang, Y., Fan, Q., Wu, W. \& Jiang, H. Copper-catalyzed synthesis of substituted quinazolines from benzonitriles and 2-ethynylanilines via carbon-carbon bond cleavage using molecular oxygen. J. Org. Chem. 83, 5458-5466 (2018).

49. Wang, X., Li, J., Huang, Y., Zhu, J., Hu, R., Wu, W. \& Jiang, H. Facile synthesis of $\pi$-conjugated quinazoline-substituted ethenes from 2-ethynylanilines and benzonitriles under transition-metal-free conditions. J. Org. Chem. 83, 10453-10464 (2018).

50. Rodrigues, R., Tran, L. Q., Darses, B., Daubana, P. \& Neuville, L. Copper-promoted tandem threecomponent access to quinazolin-4(H)-imines and benzimidazo[1,2-c]quinazolines. Adv. Synth. Catal. 361, 4454-4460 (2019). 
51. Das, K., Mondal, A., Pal, D. \& Srimani, D. Sustainable synthesis of quinazoline and 2-aminoquinoline via dehydrogenative coupling of 2-aminobenzyl alcohol and nitrile catalyzed by phosphine-free manganese pincer complex. Org. Lett. 21, 3223-3227 (2019).

52. Mao, W., Shi, W., Li, J., Su, D., Wang, X., Zhang, L., Pan, L., Wu, X. \& Wu, H. Organocatalytic and scalable syntheses of unsymmetrical 1,2,4,5-tetrazines by thiol-containing promotors. Angew. Chem. Int. Ed. 58,1106-1109 (2019).

53. Allen, C. L. \& Williams, J. M. J. Metal-catalysed approaches to amide bond formation. Chem. Soc. Rev. 40, 3405-3415 (2011).

54. García-Álvarez, R., Crochet, P. \& Cadierno, V. Metal-catalyzed amide bond forming reactions in an environmentally friendly aqueous medium: nitrile hydrations and beyond. Green Chem. 15, 46-66 (2013).

55. Karad, S. N., Chung, W.-K. \& Liu, R.-S. Gold-catalyzed formal $[4 \pi+2 \pi]$-cycloadditions of propiolate derivatives with unactivated nitriles. Chem. Sci. 6, 5964-5968 (2015).

56. Dubovtsev, A. Y., Dar'in, D. V. \& Kukushkin, V. Y. Three-component [2+ $2+1]$ gold(I)-catalyzed oxidative generation of fully substituted 1,3-oxazoles involving internal alkynes. Adv. Synth. Catal. 361, 2926-2935 (2019).

57. Chen, L.-L., Zhang, J.-W., Chen, P., Zhang, S., Yang, W.-W., Fu, J.-Y., Zhu, J.-Y. \& Wang, Y.-B. Basecontrolled divergent synthesis of 5-cyanobenzoxepines and benzofuro[2,3-b]pyridines from 2-bromophenylacetonitriles and ynones. Org. Lett. 21, 5457-5461 (2019).

58. Vanoye, L., Hammoud, A., Gérard, H., Barnes, A., Philippe, R., Fongarland, P., de Bellefon, C. \& FavreRéguillon, A. Direct synthesis of nitriles from carboxylic acids using indium-catalyzed transnitrilation: mechanistic and kinetic study. ACS Catal. 9, 9705-9714 (2019).

59. Wang, Q., Rudolph, M., Rominger, F. \& Hashmi, A. S. K. Gold-catalyzed intermolecular oxidative diyne cyclizations via 1,6-carbene transfer. Adv. Synth. Catal. 362, 755-759 (2020).

60. Chen, A. D., Herbort, J. H., Wappes, E. A., Nakafuku, K. M., Mustafa, D. N. \& Nagib, D. A. Radical cascade synthesis of azoles via tandem hydrogen atom transfer. Chem. Sci. 11, 2479-2486 (2020).

61. Bian, Q., Wu, C., Yuan, J., Shi, Z., Ding, T., Huang, Y., Xu, Y. \& Xu, H. Iron nitrate-mediated selective synthesis of 3-acyl-1,2,4-oxadiazoles from alkynes and nitriles: the dual roles of iron nitrate. J. Org. Chem. 85, 4058-4066 (2020).

62. Trose, M., Lazreg, F., Lesieur, M. \& Cazin, C. S. J. A straightforward metal-free synthesis of 2substituted thiazolines in air. Green Chem. 17, 3090-3092 (2015).

63. Natarajan, P., Manjeet, Muskan, Brar, N. K. \& Kaur, J. J. Visible light photoredox catalysis: conversion of a mixture of thiophenols and nitriles into 2-substituted benzothiazoles via consecutive $\mathrm{C}-\mathrm{S}$ and C-N bond formation reactions. Org. Chem. Front. 5, 1527-1531 (2018).

64. Zhang, W., Tao, S., Ge, H., Li, Q., Ai, Z., Li, X., Zhang, B., Sun, F., Xu, X. \& Du, Y. Construction of 2-arylbenzo[4,5]thieno[2,3- $d$ ]thiazole skeleton via CuCl/S-mediated three-component reaction. Org. Lett. 22, 448-452 (2020). 
65. Wang, H., Xu, Q., Shen, S. \& Yu, S. Synthesis of quinolines through three-component cascade annulation of aryl diazonium salts, nitriles, and alkynes. J. Org. Chem. 82, 770-775 (2017).

66. Ye, F., Tran, C., Jullien, L., Saux, T. L., Haddad, M., Michelet, V. \& Ratovelomanana-Vidal, V. Synthesis of fluorescent azafluorenones and derivatives via a ruthenium-catalyzed [2+2+2] cycloaddition. Org. Lett. 20, 4950-4953 (2018).

67. Wang, Q., Chen, X., Wang, X.-G., Liu, H.-C. \& Liang, Y.-M. Base-promoted nitrile-alkyne domino-type cyclization: a general method to trisubstituted imidazoles. Org. Lett. 21, 9874-9877 (2019).

68. Dubovtsev, A. Y., Shcherbakov, N. V., Dar'in, D. V. \& Kukushkin, V. Y. The dichotomy of gold-catalyzed interplay between cyanamides and ynamides: controllable switch from [2+2 +2] to [4 + 2] cycloaddition. Adv. Synth. Catal. 362, 2672-2682 (2020).

69. Pearce, A. J., Harkins, R. P., Reiner, B. R., Wotal, A. C., Dunscomb, R. J. \& Tonks, I. A. Multicomponent pyrazole synthesis from alkynes, nitriles, and Ti imidos via oxidatively induced $\mathrm{N}-\mathrm{N}$ bond coupling. J. Am. Chem. Soc. 142, 4390-4399 (2020).

70. Neumann, J. J., Suri, M. \& Glorius, F. Efficient synthesis of pyrazoles: oxidative C-C/N-N bondformation cascade. Angew. Chem. Int. Ed. 49, 7790-7794 (2010).

71. Chen, B., Zhu, C., Tang, Y. \& Ma, S. Copper-mediated pyrazole synthesis from 2,3-allenoates or 2alkynoates, amines and nitriles. Chem. Commun. 50, 7677-7679 (2014).

72. Jaiswal, Y., Kumar, Y., Pal, J., Subramanian, R. \& Kumar, A. Rapid synthesis of polysubstituted phenanthridines from simple aliphatic/aromatic nitriles and iodo arenes via $\mathrm{Pd}(\mathrm{II})$ catalyzed domino C-C/C-C/C-N bond formation. Chem. Commun. 54, 7207-7210 (2018).

73. Zhang, Y., Shao, Y., Gong, J., Hu, K., Cheng, T. \& Chen, J. Palladium-catalyzed tandem reaction of quinazolinone-based nitriles with arylboronic acids: synthesis of 2-(4-arylquinazolin-2-yl)anilines. Adv. Synth. Catal. 360, 3260-3265 (2018).

74. Zhou, Y., Zhou, L., Jesikiewicz, L. T., Liu, P. \& Buchwald, S. L. Synthesis of pyrroles through the CuHcatalyzed coupling of enynes and nitriles. J. Am. Chem. Soc. 142, 9908-9914 (2020).

75. del Pozo, J., Zhang, S., Romiti, F., Xu, S., Conger, R. P. \& Hoveyda, A. H. Streamlined catalytic enantioselective synthesis of $\alpha$-substituted $\beta, \gamma$-unsaturated ketones and either of the corresponding tertiary homoallylic alcohol diastereomers. J. Am. Chem. Soc. 142, 18200-18212 (2020).

76. Yadav, A., Verma, A., Patel, S., Kumar, A., Rathore, V., Meenakshi, Kumar, S. \& Kumar, S. KO'Bumediated annulation of acetonitrile with aldehyde: synthesis of substituted dihydropyridin-2 $(1 / H)$ ones, pyridin-2(1H)-ones, and thiopyridin-2(1H)-ones. Chem. Commun. 51, 11658-11661 (2015).

77. Su, L., Sun, K., Pan, N., Liu, L., Sun, M., Dong, J., Zhou, Y. \& Yin, S.-F. Cyclization of ketones with nitriles under base: a general and economical synthesis of pyrimidines. Org. Lett. 20, 3399-3402 (2018).

78. He, D., Zhuang, Z., Wang, X., Li, J., Li, J., Wu, W., Zhao, Z., Jiang, H. \& Tang, B. Z. Assembly of $1 H$ isoindole derivatives by selective carbon-nitrogen triple bond activation: access to aggregationinduced emission fluorophores for lipid droplet imaging. Chem. Sci. 10, 7076-7081 (2019). 
79. Li, D.-Y., Chen, J.-Y., Feng, D.-F., Chen, S., Xu, X.-K., Dang, L. \& Liu, P.-N. Construction of multiple bonds via a domino reaction of trifluoroacetimidoyl nitriles with in situ generated bis-nucleophiles. Chem. Commun. 56, 8222-8225 (2020).

80. Pieczykolan, M., Sadowski, B. \& Gryko, D. T. The ultimate method for the programmed synthesis of multifunctional diketopyrrolopyrroles. Angew. Chem. Int. Ed. 59, 7528-7535 (2020).

81. Li, J., Zhang, S. \& Zou, H. One-pot chemoselective domino condensation to form a fused pyrrolopyrazino-indolizine framework: discovery of novel AIE molecules. Org. Chem. Front. 7, 1218-1223 (2020).

82. Mao, J., Wang, Z., Xu, X., Liu, G., Jiang, R., Guan, H., Zheng, Z. \& Walsh, P. J. Synthesis of indoles through domino reactions of 2-fluorotoluenes and nitriles. Angew. Chem. Int. Ed. 58, 11033-11154 (2019).

83. Liu, Y.-F., Zhai, D.-D., Zhang, X.-Y. \& Guan, B.-T. Potassium-zincate-catalyzed benzylic C-H bond addition of diarylmethanes to styrenes. Angew. Chem. Int. Ed. 57, 8245-8249 (2018).

84. Zhai, D.-D., Zhang, X.-Y., Liu, Y.-F., Zheng, L. \& Guan, B.-T. Potassium amide-catalyzed benzylic C-H bond addition of alkylpyridines to styrenes. Angew. Chem. Int. Ed. 57, 1650-1653 (2018).

85. Bao, W., Kossen, H. \& Schneider, U. Formal allylic $\mathrm{C}\left(\mathrm{sp}^{3}\right)-\mathrm{H}$ bond activation of alkenes triggered by a sodium amide. J. Am. Chem. Soc. 139, 4362-4365 (2017).

86. Suzuki, H., Igarashi, R., Yamashita, Y. \& Kobayashi, S. Catalytic direct-type 1,4-addition reactions of alkylazaarenes. Angew. Chem. Int. Ed. 56, 4520-4524 (2017).

87. Yamashita, Y., Suzuki, H., Sato, I., Hirata, T. \& Kobayashi, S. Catalytic direct-type addition reactions of alkylarenes with imines and alkenes. Angew. Chem. Int. Ed. 57, 6896-6900 (2018).

88. Hussain, N., Frensch, G., Zhang, J. \& Walsh, P. J. Chemo- and regioselective C(sp $\left.{ }^{3}\right)-H$ arylation of unactivated allylarenes by deprotonative cross-coupling. Angew. Chem. Int. Ed. 53, 3693-3697 (2014).

89. Wang, Z., Zheng, Z., Xu, X., Mao, J. \& Walsh, P. J. One-pot aminobenzylation of aldehydes with toluenes. Nat. Commun. 9, 3365-3372 (2018).

90. Liu, G., Walsh, P. J. \& Mao, J. Alkaline-metal-catalyzed one-pot aminobenzylation of aldehydes with toluenes. Org. Lett. 21, 8514-8518 (2019).

91. Yin, H., Carroll, P. J. \& Schelter, E. J. Reactions of a cerium(III) amide with heteroallenes: insertion, silyl-migration and de-insertion. Chem. Commun. 52, 9813-9816 (2016).

92. Ciaccia, M. \& Stefano, S. D. Mechanisms of imine exchange reactions in organic solvents. Org. Biomol. Chem. 13, 646-654 (2015).

\section{Tables}

Due to technical limitations the tables are available as a download in the Supplemental Files.

\section{Figures}


<smiles>CCc1ccc(CCOc2ccc(CC3SC(=O)NC3=O)cc2)nc1</smiles>

I. Actos

(antidiabetics)

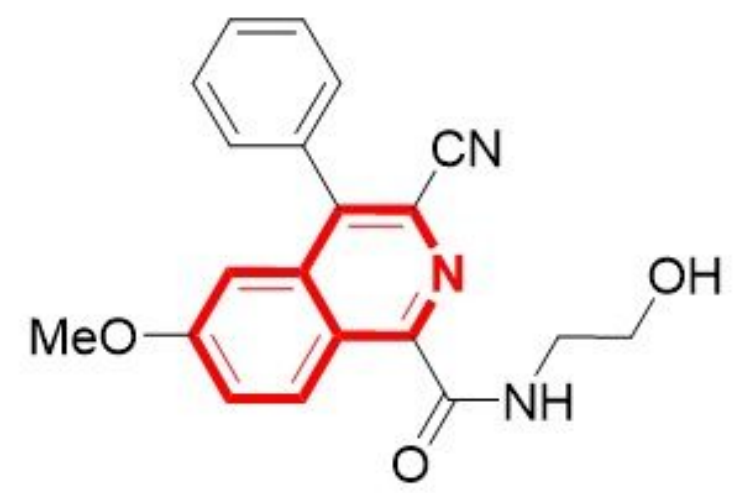

III. Kv1.5 Antagonist

(promising atrial-selective agent)

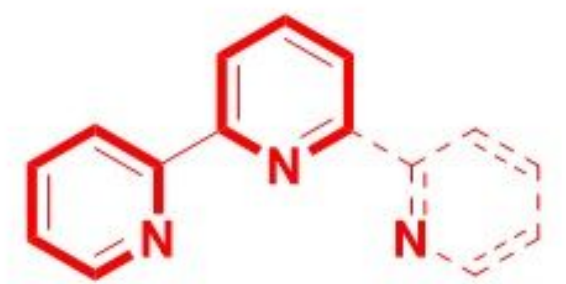

II. Bi-(or tri-) pyridines (metal ligands)

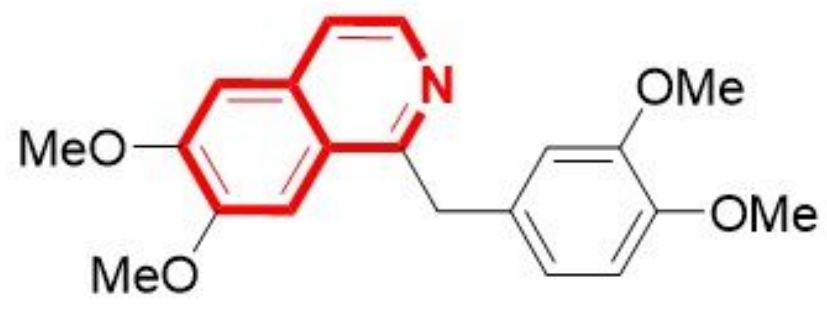

IV. Papaverine (smooth muscle relaxant)

Figure 1

Representative important pyridine derivatives 
A. Transition metal-catalyzed intramolecular cyclization of o-substituted aryl alkynes<smiles>[R]C#Cc1ccccc1C([R])[R]</smiles>

$\mathrm{R}^{1}=\mathrm{H}, \mathrm{I}$, alkyl, aryl

$\mathrm{R}^{2}$ or $\mathrm{R}^{3}=\mathrm{H}$, alkyl, aryl

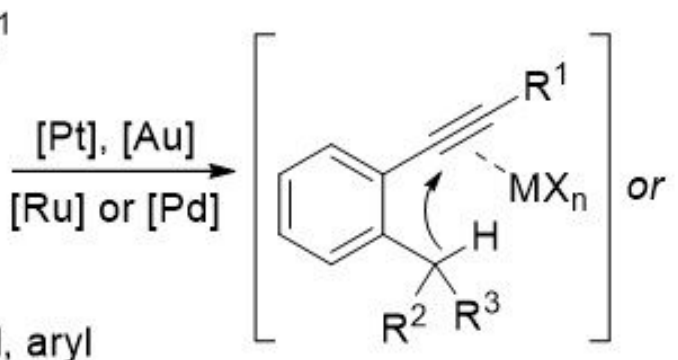

$\mathrm{R}^{1}=$ alkyl, aryl

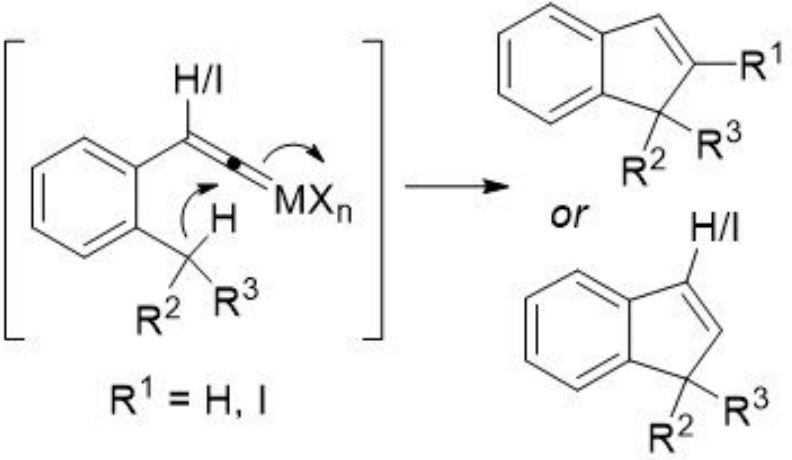

B. The development of nucleophilic addition to nitrile

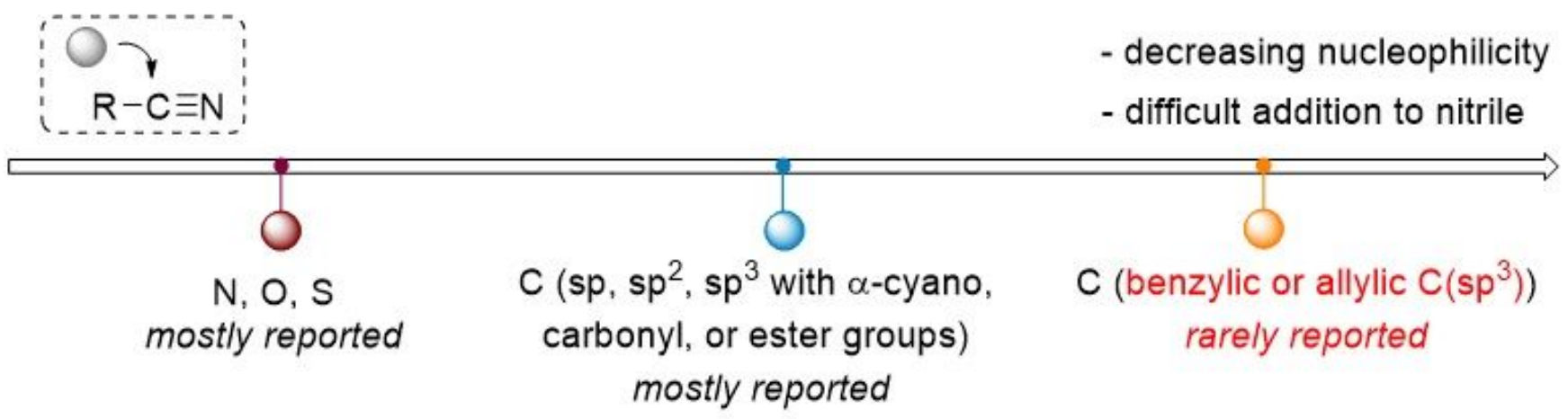

C. Alkali metal-mediated intermolecular [4+2] cycloaddition (this work)

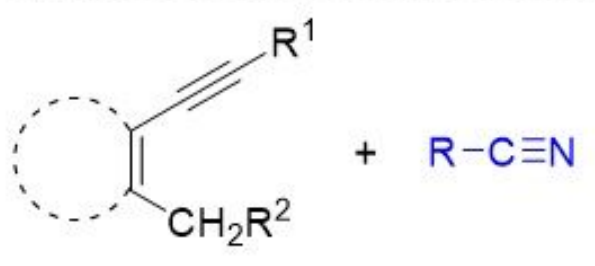

$\mathrm{R}^{1}=$ aryl, heteroaryl $\mathrm{R}=$ aryl, $\mathrm{R}^{2}=\mathrm{H}$, alkyl, aryl heteroaryl

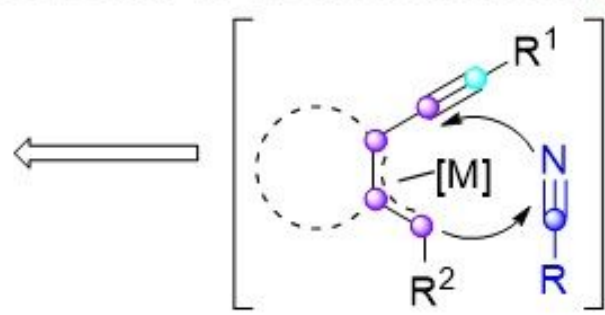

$[\mathrm{M}]=\mathrm{Li}, \mathrm{Na}$ or $\mathrm{K}$ non-classical [4+2] cycloaddition

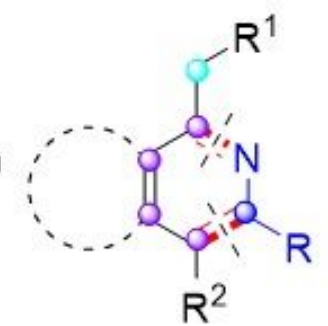

Densely Substituted Pyridine Derivatives

\section{challenges:}

- benzylic or allylic $\mathrm{C}\left(\mathrm{sp}^{3}\right)-\mathrm{H}$ bond activation - preferentially inter- to intramolecular cyclization - sequential activation of nitrile and alkyne - chemo- and regioselectivity

Figure 2

Intramolecular cyclization of o-substituted aryl alkynes $(A)$, the development of nucleophilic addition to nitrile (B) and our design (C). 


\section{a. Gram scale experiments}<smiles>COc1ccc(Cc2nc(-c3ccccc3)cc3ccccc23)cc1</smiles>

3c, $77 \% 1.25 \mathrm{~g}$ 1c $(5 \mathrm{mmol} 1.11 \mathrm{~g})$ conditions A

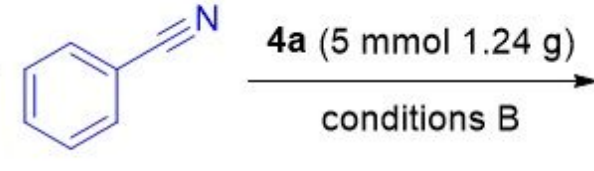

2a (2 equiv)

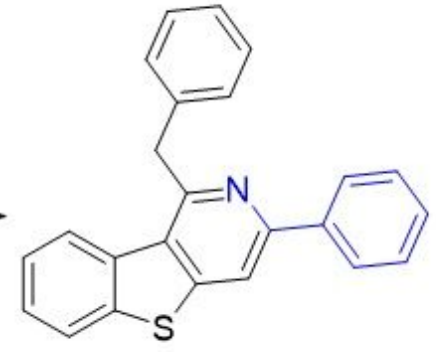

$5 a, 85 \% 1.49 \mathrm{~g}$

\section{b. Synthetic transformations}

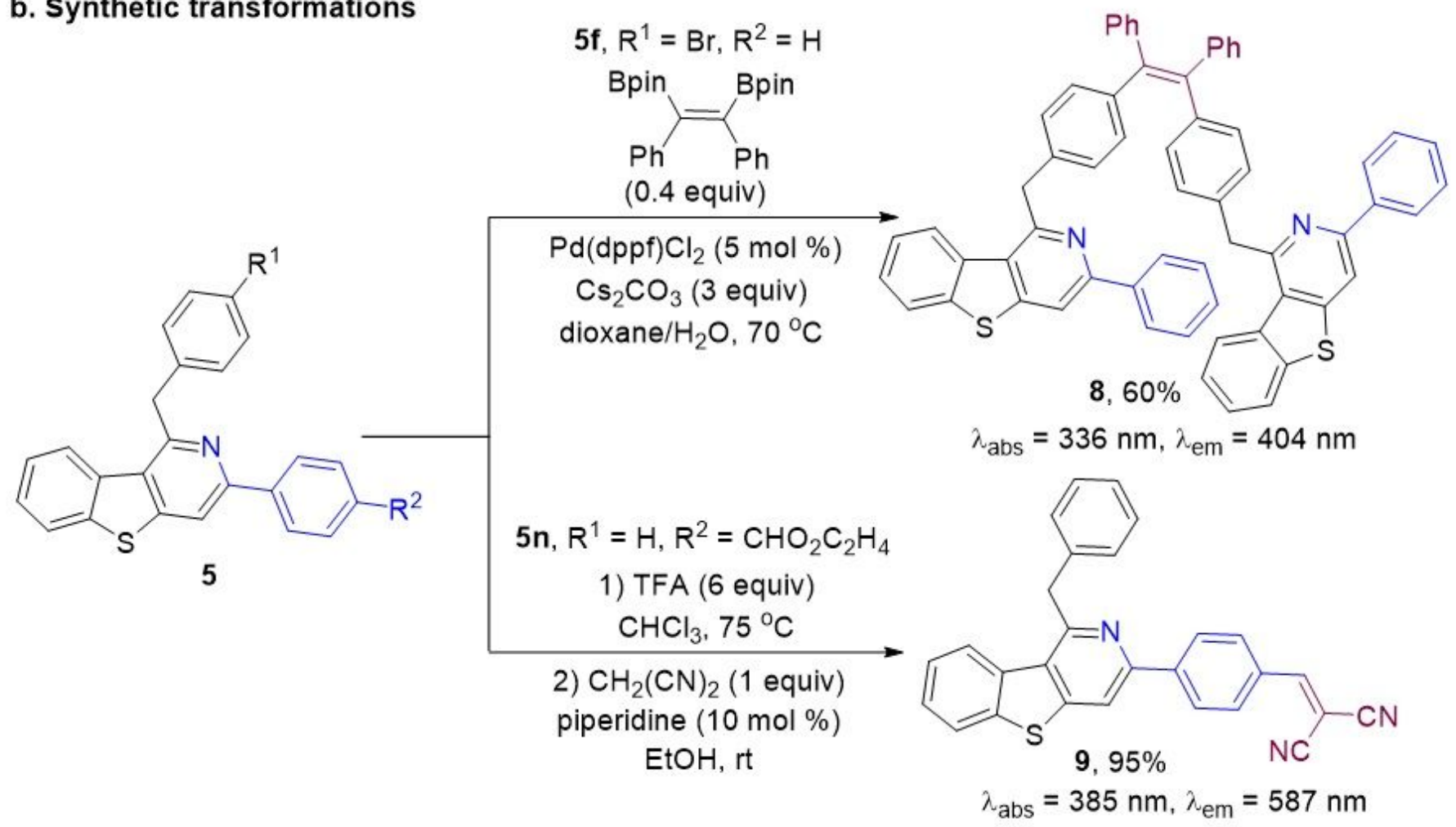

Figure 3

The gram-scale experiments and synthetic transformations 


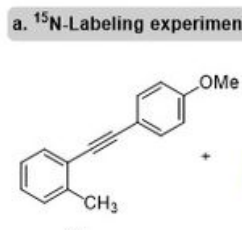

1c

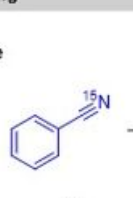

$2 a$

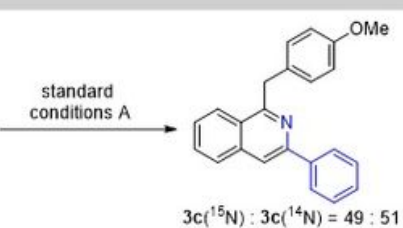

$3 \mathrm{c}\left({ }^{15} \mathrm{~N}\right): 3 \mathrm{c}\left({ }^{14} \mathrm{~N}\right)=49: 51$ $70 \%$ yield b. Effects of exogenous halogens

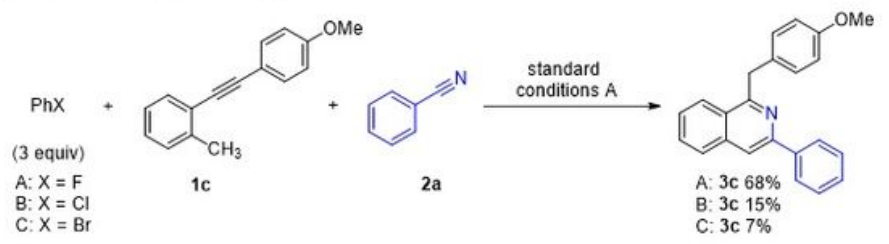

c. Hammett experiments

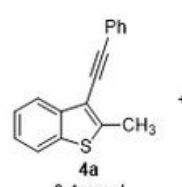

$4 \mathrm{a}$
$0.1 \mathrm{mmol}$

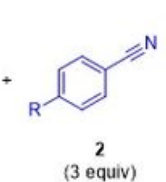

$\underset{\operatorname{LiN}(\mathrm{TMS})_{2}(2 \text { equiv })}{t \text {-BuOK }(1.2 \text { equiv })}$
$\underset{\operatorname{CPME}(0.25 \mathrm{~mL})}{120^{\circ} \mathrm{C}}$

(3 equiv)

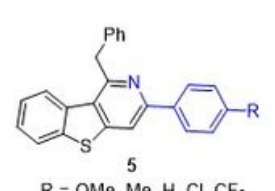

$\mathrm{R}=\mathrm{OMe}, \mathrm{Me}, \mathrm{H}, \mathrm{Cl}, \mathrm{CF}_{3}$

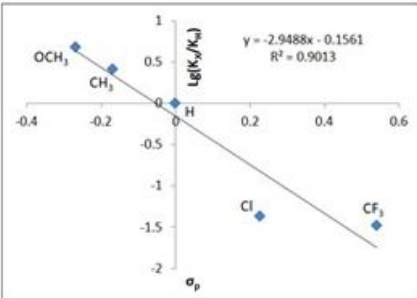

d. Determination of the order
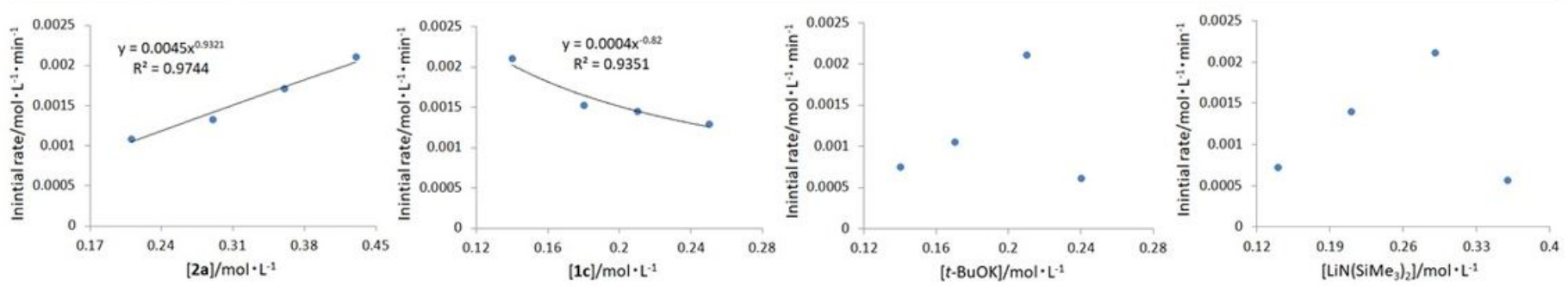

\section{Figure 4}

Mechanistic studies 


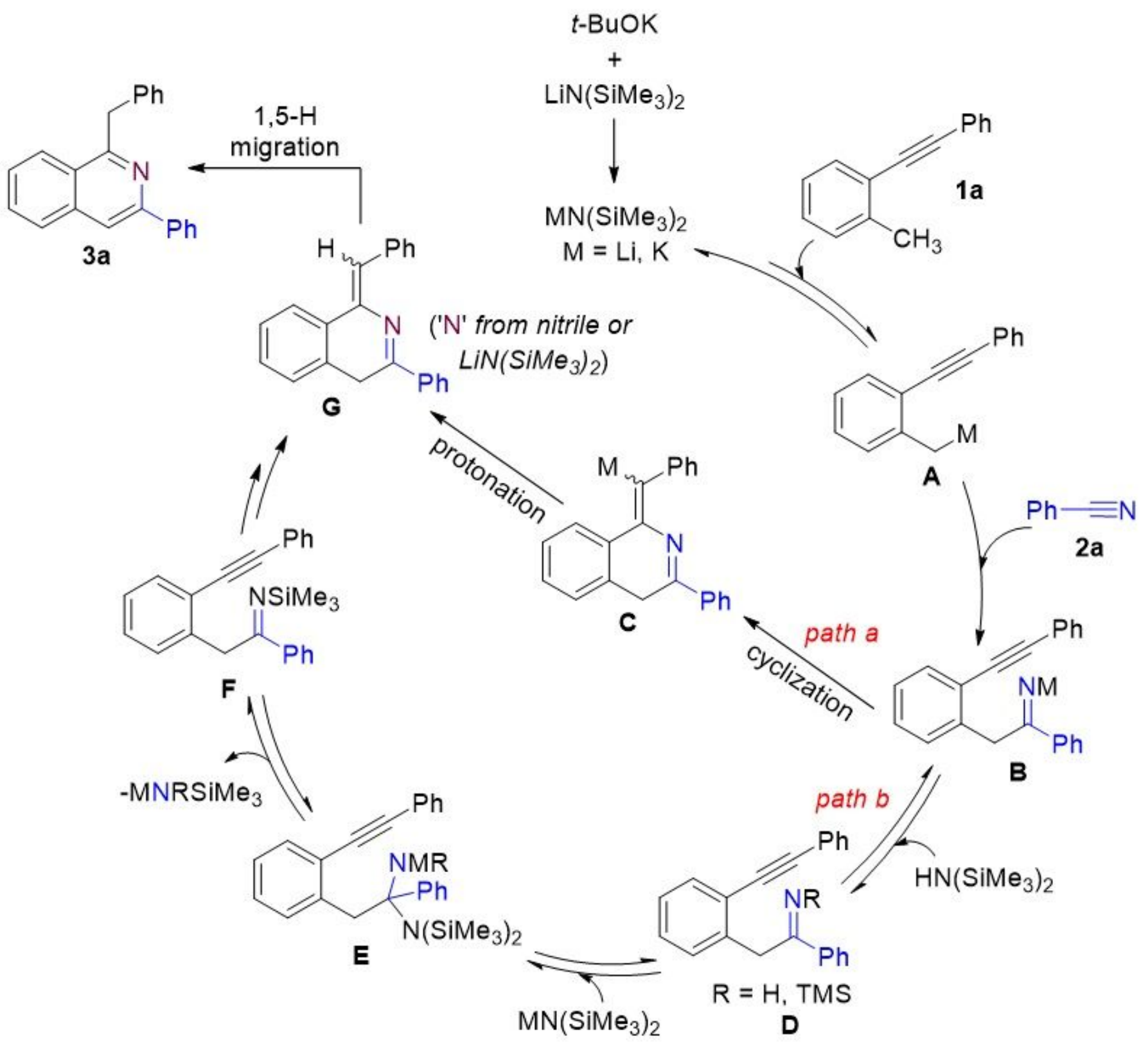

Figure 5

Possible mechanism

\section{Supplementary Files}

This is a list of supplementary files associated with this preprint. Click to download.

- NCSI20210220.docx

- Tables.pdf 